Research paper

\title{
Activated neuro-oxidative and neuro-nitrosative pathways at the end of term are associated with inflammation and physio-somatic and depression symptoms, while predicting outcome characteristics in mother and baby
}

\author{
Chutima Roomruangwong ${ }^{\mathrm{a}}$, Decio Sabbatini Barbosa ${ }^{\mathrm{b}}$, Andressa Keiko Matsumoto ${ }^{\mathrm{b}}$, \\ André de Souza Nogueira ${ }^{\mathrm{b}}$, Buranee Kanchanatawan ${ }^{\mathrm{a}}$, Sunee Sirivichayakul ${ }^{\mathrm{c}}$, André F. Carvalho ${ }^{\mathrm{d}}$, \\ Sebastien Duleu ${ }^{\mathrm{e}}$, Michel Geffard ${ }^{\mathrm{e}, \mathrm{f}}$, Estefania Gastaldello Moreira ${ }^{\mathrm{b}}$, Michael Maes ${ }^{\mathrm{a}, \mathrm{b}, \mathrm{g}, \mathrm{h}, \mathrm{i}, *}$ \\ a Department of Psychiatry, Faculty of Medicine, Chulalongkorn University, Bangkok, Thailand \\ b Graduation Program in Health Sciences, State University of Londrina, Londrina, Brazil \\ ${ }^{c}$ Department of Medicine, Faculty of Medicine, Chulalongkorn University, Bangkok, Thailand \\ d Department of Clinical Medicine and Translational Psychiatry Research Group, Faculty of Medicine, Federal University of Ceará, Fortaleza, CE, Brazil \\ e IDRPHT, Research Department, Talence, France \\ ${ }^{f}$ GEMAC, Lieu-Dit Berganton, Saint Jean d'Illac, France \\ ${ }^{g}$ Department of Psychiatry, Medical University Plovdiv, Plovdiv, Bulgaria \\ h Revitalis, Waalre, The Netherlands \\ ${ }^{\text {i }}$ IMPACT Research Center, Deakin University, Geelong, Australia
}

\section{A R T I C L E I N F O}

\section{Keywords:}

Depression

Inflammation

Immune

Cytokines

Oxidative and nitrosative stress

\begin{abstract}
A B S T R A C T
Objectives: To examine oxidative \& nitrosative stress (O\&NS) biomarkers at the end of term in relation to perinatal affective symptoms, neuro-immune biomarkers and pregnancy-related outcome variables. Methods: We measured plasma advanced oxidation protein products (AOPP), nitric oxide metabolites (NOx), total radical trapping antioxidant parameter (TRAP), -sulfhydryl (-SH), peroxides (LOOH) and paraoxonase (PON)1 activity in pregnant women with and without prenatal depression and non-pregnant controls.

Results: Pregnancy is accompanied by significantly increased AOPP and NOx, and lowered TRAP, -SH and $\mathrm{LOOH}$. Increased $\mathrm{O} \& \mathrm{NS}$ and lowered $\mathrm{LOOH}$ and -SH levels are associated with prenatal depressive and physiosomatic symptoms (fatigue, pain, dyspepsia, gastro-intestinal symptoms). Increased AOPP and NOx are significantly associated with lowered -SH, TRAP and zinc, and with increased haptoglobin and C-reactive protein levels. Increased O \& NS and lowered TRAP and PON 1 activity, at the end of term predict mother (e.g. hyperpigmentation, labor duration, caesarian section, cord length, breast milk flow) and baby (e.g. sleep and feeding problems) outcome characteristics.

Conclusions: Pregnancy is accompanied by interrelated signs of O \& NS, lowered antioxidant defenses and activated neuro-immune pathways. Increased $\mathrm{O} \& \mathrm{NS}$ at the end of term is associated with perinatal depressive and physio-somatic symptoms and may predict obstetric and behavioral complications in mother and baby.
\end{abstract}

\section{Introduction}

Depression is accompanied by oxidative and nitrosative stress (O \& NS) (Maes et al., 2016; Moylan et al., 2014), immune activation and a chronic mild inflammatory response (Maes et al., 2015, 1993). O \& NS signs include increased peroxide levels (Liu et al., 2015), increased damage to lipids (Camkurt et al., 2016; Maes, 2008), increased nitric oxide (NO) production and nitrosative stress (Maes, 2008), increased damage to proteins, as indicated by elevated levels of advanced oxidation protein products (AOPP) (Vargas et al., 2013a), and lowered levels of antioxidants, including paraoxonase (PON)1 (Barim et al., 2009; Bortolasci et al., 2014; Maurya et al., 2016), total radical trapping potential (TRAP) (Liu et al., 2015) and -sulfhydryl (-SH) groups (Cichoń et al., 2015). Furthermore, peripheral signs of immune-inflammatory activation include upregulation of positive acute phase proteins, including haptoglobin and C-reactive protein (CRP) (Maes, 1993), and downregulation of negative acute phase reactants, including zinc (Jung et al., 2016; Styczeń et al., 2016). In depression, the

\footnotetext{
* Correspondence to: IMPACT Strategic Research Center, Barwon Health, Deakin University, Geelong, Vic, Australia.

E-mail address: dr.michaelmaes@hotmail.com (M. Maes).

URL: http://scholar.google.co.th/citations? user =1 wzMZ7UAAAAJ \& $\mathrm{hl}=$ th $\&$ oi $=$ ao (M. Maes).
} 
tryptophan catabolite (TRYCAT) pathway may be activated through stimulation of indoleamine-2,3-dioxygenase (IDO) by immune and oxidative processes (Maes et al., 2011b).

Pregnancy is accompanied not only by increased immune activation (Anderson and Maes, 2013) and consequent TRYCAT pathway activation (Anderson and Maes, 2013), but also O \& NS as indicated by increased lipid peroxides (Patil et al., 2006; Walsh, 1994), production of NO metabolites (NOx) (Choi et al., 2002) and AOPP levels (Fialová et al., 2003; Kalousová et al., 2002). Antioxidant defenses are lowered during pregnancy as indicated by lowered PON1 (Rojekar and Mogarekar, 2015), TRAP (Salas-Pacheco et al., 2016), -SH (De Lucca et al., 2016) and zinc (Ma et al., 2015; Nossier et al., 2015; Tabrizi and Pakdel, 2014) levels as well as other antioxidants (Salas-Pacheco et al., 2016). Increased peripheral inflammation and O \& NS have been demonstrated to be associated with various obstetric complications, including preeclampsia (Kirbas et al., 2016; Ma et al., 2015; Nossier et al., 2015), glucose intolerance (Zein et al., 2016), miscarriage, fetal anomaly and growth restriction and preterm labor (Duhig et al., 2016; Mukhopadhyay et al., 2015). Moreover, these pathways may also affect neonate's outcomes, including lowered Apgar scores (Rejc et al., 2016), increased risk of asthma (Noutsios and Floros, 2014), poorer neurodevelopment outcome (especially among male babies) (Roy et al., 2015), and other specific diseases of the neonatal period, such as bronchopulmonary dysplasia, retinopathy of prematurity, necrotizing enterocolitis, and periventricular leukomalacia (Marseglia et al., 2014).

There is now evidence that perinatal depression and anxiety symptoms are predicted by immune activation and inflammatory responses, including lowered tryptophan availability and endogenous compounds with anti-inflammatory and antioxidant properties (Maes et al., 1992, 2000, 2001), e.g. CC16 (Maes et al., 1999), T3 popyunsaturated fatty acids (PUFAs) (De Vriese et al., 2003) and zinc, increased inflammatory cytokines and CRP levels (Anderson and Maes, 2014, 2016; Leff-Gelman et al., 2016; Roomruangwong et al., 2016a, 2016c). Recently, we published that an increased hematocrit (Hct), but not mean corpuscular volume (MCV), at the end of term may predict postnatal depressive symptoms (Roomruangwong et al., 2016b). Moreover, the severity of physio-somatic symptoms at the end of term, including fatigue, pain, dyspepsia and gastro-intestinal symptoms, is strongly associated with signs of inflammation (CRP and zinc levels) and TRYCAT pathway activation (Roomruangwong et al., 2016a).

There is, however, a paucity of data on the involvement of O \& NS processes in perinatal depression. There is one paper hypothesizing that increased oxidative stress in perinatal depression could contribute to cardiovascular pathology in women with pre-eclampsia (Nicholson et al., 2016). Nevertheless, elevated O \& NS in pregnancy may have detrimental effects by increasing the risk towards perinatal depression and physio-somatic symptoms. Indeed, increased O \& NS processes are associated not only with the onset of depression (Maes et al., 2011a), but also physio-somatic symptoms (Maes et al., 2006; Morris and Maes, 2013). In addition, O \& NS processes could play a role in pathophysiological underpinnings of perinatal depression, including immune activation, inflammation and lowered T3 PUFA levels (Moylan et al., 2014). The erythron, including erythrocyte morphology, is in part modulated by increased oxidative stress and reduced levels of antioxidants (Lurie and Mamet, 2000; Peng and Pan, 2017; Tiwari et al., 2012; Waggiallah and Alzohairy, 2011).

This study aimed to examine whether O \& NS biomarkers, namely AOPP, LOOH, NOx, -SH groups, TRAP, and PON1 activities in pregnant women could be associated with depressive, physio-somatic and anxiety symptoms, inflammatory biomarkers, namely CRP, haptoglobin and zinc, TRYCAT pathway activation, erythron variables, including Hct, and mother and baby outcome variables. The a priori hypotheses are that a) pregnancy is accompanied by signs of O \& NS including lowered antioxidant defenses, b) the latter are associated with perinatal affective symptoms and immune activation, and c) increased O \& NS predicts selected obstetric and behavioral complications for mother and baby.

\section{Participants and methods}

\subsection{Participants}

We recruited 24 non-pregnant women and 49 pregnant women who attended the Antenatal Clinic of the King Chulalongkorn Memorial Hospital, Bangkok, Thailand. Participants were included when they were 18 years of age or older and being able to read and write Thai language. We only included pregnant women who did plan to give birth and attend postnatal follow up consultations at the Department of Gynecology, King Chulalongkorn Memorial Hospital. We excluded pregnant women with positive VDRL or HIV serology, and medical or obstetric condition(s) that impede ability to fill in the questionnaires and women with any DSM-IV-TR axis I disorders, other than mood disorders (bipolar disorder and major depression), e.g. autism, schizophrenia, cognitive disorders and substance abuse. We excluded pregnant and non-pregnant women with medical disorders, such as (auto) immune disorders, diabetes, hypertension, chronic obstructive pulmonary disease, heart failure. Exclusionary criteria for normal controls were a lifetime or current diagnosis of any axis 1 disorders. The study was approved by the Ethics Committee of the Faculty of Medicine, Chulalongkorn University, Bangkok, Thailand. Written informed consent was obtained from all participants.

\subsection{Measures}

All pregnant and non-pregnant women were assessed by a senior psychiatrist using a structured interview, which included the 17-item Hamilton Depression Rating Scale (HDRS) (Hamilton, 2000; Lotrakul et al., 1996), the Beck Depression Inventory (BDI) (Beck et al., 1988; Horasut et al., 1997), the Edinburgh Postnatal Depression Scale (EPDS), Thai validated translation (Pitanupong et al., 2007; Vacharaporn et al., 2003), Spielberger's State-Trait Anxiety Inventory (STAI), state version in a Thai validated translation (Spielberger and Vagg, 1984) and the Mini International Neuropsychiatric Interview (M.I.N.I) - Thai version to assess the diagnosis of "a life time history of mood disorders" (namely major depression, bipolar disorder or dysthymia) and "a life time history of depression" (namely major depression or dysthymia) (Sheehan et al., 1998). A senior psychiatrist and a senior gynecologist evaluated pregnant women at 2 time points, namely end of term (T1) and 4-6 weeks after delivery (T2). Pregnant women with a T1 EPDS score $\geq 11$ were considered to have a positive screening for antenatal depression (Pitanupong et al., 2007; Vacharaporn et al., 2003). The senior research psychiatrist also assessed criteria for premenstrual syndrome (PMS), i.e. a recurrent pattern of mood (sadness, depression, anxiety, irritability, tension and lowered concentration) and physiosomatic (tender breasts, fatigue, body aches, bloating) symptoms, which appear in the luteal phase and resolve with menstruation. At T1, the senior psychiatrist assessed hyperpigmentation and physio-somatic symptoms, including fatigue, back pain, muscle pain, dyspepsia and obstipation. In addition, at T1 we assessed body weight (in kilograms, $\mathrm{kg}$ ) with a digital weighing scale and height (in meter, $\mathrm{m}$ ) with a manual height measure instrument and computed body mass index (BMI) as body weight $(\mathrm{kg}) /$ height $(\mathrm{m})^{2}$. At T2, the senior psychiatrist assessed mother and baby characteristics including baby sucking problems and inadequate breast milk flow in the first week after delivery, number of baby awakenings and total time of baby awakenings during the night the first 4 weeks after delivery. Medical and obstetric data, including caesarian section, duration of labor and placenta weight were obtained from medical records.

At 8.00 a.m. fasting $(10 \mathrm{~h})$ blood was collected in non-pregnant and pregnant (at T1) women for the measurement of serum O \& NS and antioxidant biomarkers, including lipid peroxides, AOPP, NOx, TRAP, -SH groups, PON1 activities. Hydroperoxide (LOOH) was determined according to an adaptation of the technique described by GonzalesFlecha et al. (Gonzalez Flecha et al., 1991) and Panis et al. (Panis et al., 
2012). This method uses the compound tert-butyl hydroperoxide to start a lipid chain reaction that can be detected by photon emission during the formation of lipid hydroperoxides. Readings were performed in a Glomax luminometer (TD 20/20 Turner Designers, E.U.A.) over $1 \mathrm{~h}$ at 1 readings/s. Results were expressed as relative units of light (RUL). To measure protein oxidation, AOPP in plasma was quantified using the method described by Hanasand et al. (Hanasand et al., 2012) in a microplate reader, Perkin Elmer ${ }^{\circledR}$, model EnSpire (Waltham, MA, EUA) at a wavelength of $340 \mathrm{~nm}$. AOPP concentration was expressed in $\mu \mathrm{M}$ of equivalent chloramine T. NO metabolite (NOx) levels were assessed indirectly by determining the plasma nitrite concentration using an adaptation of the technique described Navarro-Gonzálvez et al. (Navarro-Gonzálvez et al., 1998). This method is based on the reduction of the nitrate present in the sample to nitrite by oxidation-reduction reactions mediated by the system cadmium-copper reagent. Thereafter, Griess reagent was added to induce diazotization, forming a colored complex and subsequent detection at $540 \mathrm{~nm}$. The quantification of NOx was made in a microplate reader Asys Expert Plus, Biochrom ${ }^{\circ}$ (Holliston, MA, USA). The nitric oxide concentration was expressed in $\mu \mathrm{M}$. TRAP was evaluated according to the method described by Repetto et al. (1996) in microplate reader Victor X-3, Perkin Elmer (Waltham, MA, USA). Experimental conditions were: running time of $25 \mathrm{~min}$, response range from 300 to $620 \mathrm{~nm}$ and a temperature of $30{ }^{\circ} \mathrm{C}$. This method detects hydro and/or lipossoluble antioxidants present in serum. The results were expressed in $\mu \mathrm{M}$ trolox. Sulfhydryl (-SH) groups from proteins were evaluated by the method described by Hu (1994), which is based on the reaction of 5,5-dithiobis-2 nitrobenzoic acid (DTNB) with sulfhydryl groups. Determination was conducted in a spectrophotometer Helios $\alpha$, Thermo Spectronic ${ }^{\varpi}$ (Waltham, MA, USA) at $412 \mathrm{~nm}$. Results are expressed as $\mu \mathrm{M} / \mathrm{mg}$ of plasmatic protein. Total plasmatic activity of PON1 was determined by the method described by Richter et al. (Richter et al., 2008). The rate of hydrolysis of phenyl acetate was determined in a microplate reader EnSpire, Perkin Elmer (Waltham, MA, USA) at $270 \mathrm{~nm}$ and the temperature maintained at $25^{\circ} \mathrm{C}$. Measures were recorded for 4 min each $15 \mathrm{~s}$. The activity was expressed in $\mathrm{U} / \mathrm{mL}$ based on the phenyl acetate molar extinction coefficient of $1.31 \mathrm{mMol} / \mathrm{L} \mathrm{cm}^{-1}$. PON1 status (Q192R polymorphism and activity) was determined through kinetic assays (Richter et al., 2008) in a spectrophotometer microplate reader (EnSpire, Perkin Elmer, USA). Individuals were stratified in functional genotypes for PON1 Q192R polymorphism (QQ, QR and RR). Total plasmatic PON1 activity was determined by measuring rates of phenylacetate (PA, Sigma, USA) hydrolysis at low salt concentration since under this assay condition, the PON1 Q192R polymorphism does not influence PON1 catalytic activity against PA (Furlong et al., 2006). Moreover, we also present PON1 CMPAase activity which was determined by measuring rates of 4(chloromethyl)phenyl acetate (CMPA, Sigma, USA), an alternative to the use of the toxic paraoxon. CMPAase parallels the POase activity reported in some papers and both are influenced by the PON1 Q192R polymorphism since $Q$ allozyme presents low efficacy to metabolize CMPA (or paraoxon). We also determined serum CRP, haptoglobin and zinc (Roomruangwong et al., 2016c) and IgA responses to tryptophan and tryptophan catabolites (Roomruangwong et al., 2016a) as described previously. Hct and MCV [47] were assayed using an automated cell counter, Mindray BC 6800 (Shenzhen Mindray Bio-Medical Electronics, China). The intra-assay $\mathrm{CV}$ values of all analytes were less than $10 \%$.

\subsection{Statistical analysis}

Analyses of contingency tables ( $\mathrm{X}^{2}$-test) were used to check associations between sets of categorical variables, while analyses of variance (ANOVAs) were used to assess differences in continuous variables between groups. Pearson's product moment correlation analyses were used to check univariate correlations between continuous variables. Automatic stepwise multiple regression analyses were performed to delineate the most significant predictors of $\mathrm{T} 1$ physio-somatic symptoms, T2 rating scales, zIgA KYN/TRY ratio (see further), duration of labor, placenta weight and duration of baby awakenings the first week after child birth. Multivariate general linear model (GLM) analyses were employed to check the multivariate effects of predictor variables on dependent variables. For example, we used the O \& NS biomarkers as dependent variables and pregnancy and depression diagnoses or severity ratings as explanatory variables while adjusting for age and PON1 genotypes. Tests for between-subjects effects were consequently used to assess protected univariate effects of the significant explanatory variables on each of the dependent variables. Automatic stepwise binary regression analyses were used to delineate the most significant predictor variables of dichotomous mother and baby characteristics, including T1 hyperpigmentation, caesarian section, baby sucking problems and inadequate breast milk flow. The odds ratio and 95\% confidence intervals were computed. We used Ln transformations where needed to normalize the data distribution of the biomarkers, namely AOPP, NOX, PON1 and CRP. We computed z-values of biomarker variables and used z-unit weighted composite scores, namely zAOPP + zNOx $(\mathrm{zAOPP}+\mathrm{NOx})$ as an index of O\&NS, zTRAP + zCMPAase (zTRAP + CMPA) as an index of antioxidant defenses, zAOPP + NOx zTRAP + CMPA (zOX/ANTIOX) as an index of oxidative versus antioxidant ratio, and zIgA directed against kynurenine - zIgA directed against tryptophan (zIgA KYN/TRY) as an index of TRYCAT pathway activation (Maes et al., 2011b). Results of regression analyses were checked for collinearity. All statistical analyses were performed using IBM SPSS windows version 22. Tests were 2-tailed and a p-value of 0.05 was used for statistical significance.

\section{Results}

\subsection{Descriptive statistics}

Table 1 displays the socio-demographic and biomarker data of pregnant and non-pregnant women. Age was not significantly different among the study groups. T1 EPDS, HDRS and BDI were significantly higher in pregnant than in non-pregnant women, whilst T1 STAI was significantly lower in pregnant women. PC physio-somatic symptoms was significantly higher in pregnant than in non-pregnant women. CRP, haptoglobin and zinc were significantly different between both groups. The zIgA KYN/TRY ratio was significantly lower in pregnant than in non-pregnant females. AOPP, NOx, zAOPP + NOx and zOX/ANTIOX values were significantly higher in pregnant as compared to nonpregnant women. LOOH, TRAP, -SH groups and zTRAP + CMPA were significantly lower in pregnant than in non-pregnant women. Nevertheless, we underscore that we did not use p-corrections to interpret these results as these univariate tests (and the Pearson and point-biserial correlation matrices between the variables) were only employed to delineate the predictor variables that were subsequently used as independent predictors in the ultimate multivariate GLM and binary logistic regression analyses.

\subsection{Effects of pregnancy on $O \& N S$ biomarkers}

Table 2 shows the results of a multivariate GLM analyses with all O \& NS biomarkers measured in this study together with zAOPP + NOx, zTRAP + CMPA and zOX/ANTIOX as dependent variables, while pregnancy, diagnosis of antenatal depression (AND), a lifetime diagnosis of depression, age and genotype ( $R R$ versus $Q Q+Q R)$ were used as explanatory variables. Pregnancy and PON1 genotype showed significant effects on the $\mathrm{O} \&$ NS markers. Tests for between-subject effects showed similar effects of pregnancy on O\&NS biomarkers, as presented in Table 1. PON1 total activity was only associated with RR genotypes, while there were no differences in CMPAase activity between the groups. 
Table 1

Sociodemographic, clinical and biomarker data in pregnant and non-pregnant women.

\begin{tabular}{|c|c|c|c|c|c|}
\hline Variables & $\begin{array}{l}\text { Non- } \\
\text { pregnant } \\
(n=24)\end{array}$ & $\begin{array}{l}\text { Pregnant } \\
(n=49)\end{array}$ & $\mathbf{F}$ & df & $p$ \\
\hline Age (years) & $28.1(3.2)$ & $28.5(6.7)$ & 0.07 & $1 / 71$ & 0.792 \\
\hline EPDS & $4.3(3.0)$ & $8.8(6.6)$ & 9.67 & $1 / 70$ & 0.003 \\
\hline STAI-state & $49.6(6.3)$ & $42.5(10.9)$ & 9.38 & $1 / 70$ & 0.003 \\
\hline HDRS & $3.3(2.3)$ & $7.8(5.6)$ & 14.04 & $1 / 70$ & $<0.001$ \\
\hline BDI & $1.8(1.9)$ & $10.6(8.0)$ & 26.88 & $1 / 70$ & $<0.001$ \\
\hline $\begin{array}{l}\text { PC Physio-somatic } \\
\text { symptoms }\end{array}$ & $-1.12(0.0)$ & $0.19(0.94)$ & 46.02 & $1 / 71$ & $<0.001$ \\
\hline BMI $(\mathrm{kg} / \mathrm{m} 2)$ & $20.5(2.7)$ & $26.6(4.8)$ & 32.82 & $1 / 71$ & $<0.001$ \\
\hline $\begin{array}{l}\text { hs-C-reactive protein } \\
\qquad(\mathrm{mg} / \mathrm{dL})\end{array}$ & $1.6(2.0)$ & $5.1(4.8)$ & 11.66 & $1 / 70$ & 0.001 \\
\hline Zinc $(: g / d L)$ & $93.0(10.1)$ & 75.9 (12.9) & 32.39 & $1 / 69$ & $<0.001$ \\
\hline Haptoglobin (g/L) & $1.17(0.43)$ & $0.93(0.49)$ & 4.97 & $1 / 70$ & 0.029 \\
\hline $\begin{array}{c}\text { IgA KYN-TRP } \\
\text { (z-value) }\end{array}$ & $0.52(0.55)$ & $-0.26(1.02)$ & 12.34 & $1 / 71$ & 0.001 \\
\hline AOPP $(\mu \mathrm{M})$ & $73.0(21.0)$ & $202.6(85.1)$ & 111.24 & $1 / 71$ & $<0.001$ \\
\hline $\mathrm{LOOH}\left(\mathrm{RLU} \times 10^{6}\right)$ & $261.6(104.4)$ & $183.4(542.0)$ & 14.00 & $1 / 71$ & $<0.001$ \\
\hline $\mathrm{NOx}(\mu \mathrm{M})$ & $16.7(7.3)$ & $31.7(9.8)$ & 44.10 & $1 / 71$ & $<0.001$ \\
\hline TRAP ( $\mu \mathrm{M}$ trolox $)$ & $815.2(68.9)$ & $743.5(101.8)$ & 9.68 & $1 / 71$ & 0.003 \\
\hline -SH groups $(\mu \mathrm{M})$ & 294.4 (50.9) & $237.5(36.8)$ & 29.63 & $1 / 71$ & $<0.001$ \\
\hline $\begin{array}{l}\text { PON1 total activity } \\
(\mathrm{U} / \mathrm{mL})\end{array}$ & $266.9(83.8)$ & 260.8 (107.7) & 0.34 & $1 / 71$ & 0.562 \\
\hline $\begin{array}{l}\text { CMPAase activity } \\
(\mathrm{U} / \mathrm{mL})\end{array}$ & $50.0(15.1)$ & 44.7 (12.6) & 2.48 & $1 / 71$ & 0.119 \\
\hline $\begin{array}{l}\text { PON1 genotype } \\
\text { (QQ/QR/RR) }\end{array}$ & $2 / 8 / 14$ & $5 / 20 / 24$ & 0.57 & 2 & 0.745 \\
\hline $\begin{array}{c}\text { zAOPP + NOx } \\
\text { (z-value) }\end{array}$ & $-1.99(0.77)$ & $0.97(1.24)$ & 114.87 & $1 / 71$ & $<0.001$ \\
\hline $\begin{array}{c}\text { zTRAP + CMPAase } \\
\text { (z-value) }\end{array}$ & $0.75(1.13)$ & $-0.37(1.52)$ & 10.20 & $1 / 71$ & 0.002 \\
\hline $\begin{array}{c}\text { zOX/ANTIOX } \\
\text { (z-value) }\end{array}$ & $-2.74(1.36)$ & $1.34(2.03)$ & 79.36 & $1 / 71$ & $<0.001$ \\
\hline
\end{tabular}

All values are shown as mean $( \pm \mathrm{SD})$. F: all results of analyses of variance; $\mathrm{X}^{2}$ : all results of chi-square tests (analyses of contingency tables).

EPDS: Edinburgh Postnatal Depression Scale; STAI: Spielberger's State-Trait Anxiety Inventory; HDRS: The Hamilton Rating Scale for Depression; BDI: Beck Depression Inventory.

BMI: Body Mass Index $\left(\mathrm{Kg} / \mathrm{m}^{2}\right)$.

IgA KYN/TRY: IgA directed to kynurenine - IgA directed to tryptophan.

AOPP: Advanced oxidation protein products.

LOOH: Hydroperoxide.

NOx: Nitric oxide metabolites.

TRAP: Total radical trapping potential.

-SH groups: -Sulfhydryl groups.

PON1 total activity: paraoxonase 1 total activity determined using phenylacetate as substrate.

CMPAase: PON1 activity determined using CMPA (4-(chloromethyl)phenyl acetate) as substrate.

zAOPP + NOx: sum of $z$ values of AOPP and NOx.

zTRAP + CMPAase: sum of $z$ values of TRAP + CMPAase.

ZOX/ANTIOX: zAOPP + NOx/ zTRAP + CMPAase.

\subsection{Associations among $O \&$ NS biomarkers and prenatal symptomatology}

Table 3 (regressions \#1 - 4) shows the results of multivariate GLM analyses with T1 EPDS, STAI, BDI and HDRS values as dependent variables and the O \& NS and antioxidant biomarkers together with a lifetime diagnosis of depression as explanatory variables. Regression \#1 shows that both AOPP and a lifetime diagnosis of depression had significant effects on the $\mathrm{T} 1$ rating scale scores. Tests for between-subject effects showed positive associations between AOPP and EPDS, BDI and HDRS, while AOPP was negatively associated with the STAI score. Multivariate GLM analyses \#2 - 4 show that also NOx, LOOH and -SH groups had significant effects on the 4 rating scales. Tests for betweensubject effects show that NOx is inversely associated with T1 STAI $(\mathrm{F}=9.01, \mathrm{df}=1 / 68, \mathrm{p}=0.004)$, LOOH with the BDI $(\mathrm{F}=4.16, \mathrm{df}=1 / 68$, $\mathrm{p}=0.045)$ and $-\mathrm{SH}$ groups $(\mathrm{F}=6.51, \mathrm{df}=1 / 68, \mathrm{p}=0.013)$ inversely with BDI.
Moreover, zAOPP + NOx $(\mathrm{F}=10.61, \mathrm{df}=4 / 65, \mathrm{p}<0.001)$ and $\mathrm{zOX} /$ ANTIOX $(\mathrm{F}=7.59, \mathrm{df}=4 / 65, \mathrm{p}<0.001)$ had significant effects on the 4 rating scales. Tests for between-subjects effects showed that zAOPP + NOx and zOX/ANTIOX were both significantly and positively associated with HDRS and BDI and inversely with STAI scores. There were no significant effects of PON1 and CMPAase activities on T1 rating scale scores.

\subsection{Associations among $O \& N S$, antioxidant and immune-inflammatory biomarkers}

Table 4, regressions \# 1 and 2, shows the associations between inflammatory and O \& NS biomarkers. Regression \#1 shows that $-\mathrm{SH}$ groups and NOx had significant effects on CRP, haptoglobin and zinc. Tests for between-subject effects showed that CRP was associated with -SH groups (inversely) and NOx (positively), while haptoglobin (positively) and zinc (negatively) were associated with NOx. Regression \#2 shows that -SH groups together with AOPP had significant effects on the three inflammatory biomarkers. Tests for between-subject effects showed that CRP was associated with -SH groups (inversely) and AOPP (positively), while zinc was negatively associated with AOPP.

The same table (regression \#3 and 4) shows the associations between O \& NS markers, on the one hand, and antioxidants, on the other. -SH groups, TRAP and zinc, but not PON1 total and CMPAase activities, had significant effects on O \& NS markers, while tests for betweensubject effects showed that $-\mathrm{SH}$ groups were significantly and inversely associated with AOPP, NOx and zAOPP + NOx. Regression \#4 shows that TRAP was significantly and inversely associated with the three O \& NS indicants. Regression \#5 shows that zinc was inversely associated with AOPP, NOx and zAOPP + NOx and positively with $\mathrm{LOOH}$ levels.

Regression \# 6 shows the results of a multivariate GLM analysis with MCV and Hct as dependent variables and O \& NS, antioxidant and immune biomarkers as explanatory variables. Mean $( \pm S D)$ values in the pregnant women were: MCV: $79.5 \pm 8.5 \mathrm{fl}$ and Htc: $34.33 \pm 2.78 \%$ $(\mathrm{n}=44)$. Tests for between-subject effects showed that CRP was positively associated with Hct and LOOH positively with MCV.

\subsection{Associations among $O \&$ NS biomarkers and physio-somatic and postpartum symptoms}

Table 5 shows the results of stepwise multiple regression analyses with $\mathrm{T} 1$ physio-somatic symptoms and $\mathrm{T} 2$ rating scales as dependent variables. We found that $35.0 \%$ of the variance in T1 PC physio-somatic symptoms (regression \#1) was explained by zOX/ANTIOX (positively), $\mathrm{LOOH}$ and $-\mathrm{SH}$ groups (both negatively). After introducing the inflammatory biomarkers in the analysis (regression \#2), we found that $48.7 \%$ of the variance in PC physio-somatic symptoms was explained by CRP (positively), zinc and PON1 total activity (both negatively). Regressions $3-5$ show that $20.6 \%$ of the variance in T2 HDRS was explained by the regression on zAOPP $+\mathrm{NOx}$ (positively) and $\mathrm{LOOH}$ (negatively), while zAOPP + NOx explained $14.7 \%$ of the variance in T2 BDI (positive association) and $38.0 \%$ of the variance in STAI score (inversely).

Table 5 shows also the results of stepwise multiple regression analyses with T1 zIgA KYN/TRY ratio as dependent variable. The zIgA KYN/ TRY ratio (regressions \#6-8) was significantly predicted by zAOPP + NOx $(24.3 \%$ of the variance), AOPP alone $(20.7 \%)$ or NOx and CRP (21.1\%).

\subsection{Associations among $O \& N S$ and mother and baby characteristics}

The mean $(\forall S D)$ values of obstetrical and demographical data in pregnant women included in this study are as follows, number of prior pregnancies: $1.9(\forall 1.0$; range: $1-5)$, gestational age at birth: $38.8(\forall 1.3)$ weeks, duration labor: $420(\forall 317)$ minutes, placenta weight: 642 
Table 2

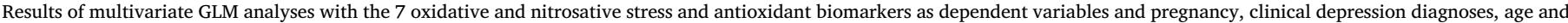
PON1 genotypes as explanatory variables.

\begin{tabular}{|c|c|c|c|c|c|c|}
\hline Tests & Dependent Variables & Explanatory variables & $\mathbf{F}$ & Df & $p$ & Partial Eta Squared \\
\hline \multirow[t]{5}{*}{ Multivariate } & 7 biomarkers and & Pregnancy & 19.93 & $7 / 61$ & $<0.001$ & 0.696 \\
\hline & $\mathrm{zAOPP}+\mathrm{NOx}$ and & RR Genotype & 8.62 & $7 / 61$ & $<0.001$ & 0.497 \\
\hline & zTRAP + CMPAase and & Lifetime MDD & 0.95 & $7 / 61$ & 0.474 & 0.098 \\
\hline & zOX/ANTIOX & Antenatal depression & 0.62 & $7 / 61$ & 0.739 & 0.066 \\
\hline & & Age & 2.14 & $7 / 61$ & 0.053 & 0.197 \\
\hline \multirow[t]{9}{*}{ Between-subject effects } & AOPP & Pregnancy & 86.45 & $1 / 67$ & $<0.001$ & 0.563 \\
\hline & $\mathrm{LOOH}$ & Pregnancy & 8.72 & $1 / 67$ & 0.004 & 0.115 \\
\hline & NOx & Pregnancy & 36.95 & $1 / 67$ & $<0.001$ & 0.355 \\
\hline & TRAP & Pregnancy & 4.75 & $1 / 67$ & 0.033 & 0.066 \\
\hline & -SH groups & Pregnancy & 18.37 & $1 / 67$ & $<0.001$ & 0.215 \\
\hline & PON1 total activity & RR Genotype & 14.53 & $1 / 67$ & $<0.001$ & 0.178 \\
\hline & $\mathrm{zAOPP}+\mathrm{NOx}$ & Pregnancy & 89.89 & $1 / 67$ & $<0.001$ & 0.573 \\
\hline & zTRAP + CMPAase & Pregnancy & 6.44 & $1 / 67$ & 0.013 & 0.088 \\
\hline & zOX/ANTIOX & Pregnancy & 57.86 & $1 / 67$ & $<0.001$ & 0.463 \\
\hline
\end{tabular}

AOPP: Advanced oxidation protein products; LOOH: Hydroperoxide; NOx: Nitric oxide metabolites; TRAP: Total radical trapping potential.

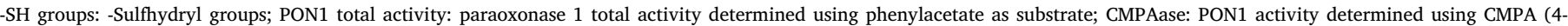
(chloromethyl)phenyl acetate) as substrate.

zAOPP + NOx: sum of $z$ values of AOPP and NOx.

zTRAP + CMPAase: sum of $z$ values of TRAP + CMPAase.

zOX/ANTIOX: zAOPP + NOx - zTRAP + CMPAase.

$(\forall 122)$ g, cord length: $50.1(\forall 12.6) \mathrm{cm}$, education: $14.1(\forall 4.1)$ years and income $77.164(\forall 12331)$ baht / month. Fifty-three \% of women were married. Hyperpigmentation was detected in 19 pregnant women, while caesarian section was performed on 23 women and 17 women had inadequate breast milk flow the first week after delivery. Baby characteristics are as follows, baby weight: $2.98(\forall 0.45) \mathrm{kg}$, baby length: $48.9(\forall 1.9) \mathrm{cm}$, Apgar score (5 min): 9.9 ( $\forall 0.3$, range: $9-10)$ and duration of baby awakenings during first 4 weeks after delivery: $30.9(\forall 29.2)$ minutes. Ten babies showed sucking problems the first week after delivery. Table 5 (regressions 9-11) shows the results of stepwise multiple regression analyses with duration of labor, placenta weight and baby awakenings as dependent variables and O \& NS and antioxidant biomarkers as explanatory variables. $24.1 \%$ of the variance in labor duration (regression \#9) was explained by the regression on PON1 total activity and CRP (both negatively). Up to $33.1 \%$ of the variance in cord length (regression \#10) was associated with AOPP (negatively) and PON1 (positively), while $42.7 \%$ of the variance in duration of baby awakenings (regression \#11) was associated with PON1 total activity and RR genotype (both inversely).

Table 6 shows the results of automatic stepwise binary logistic regression analyses with mother and baby characteristics as dependent variables and the O\&NS and antioxidant biomarkers as explanatory variables. T1 hyperpigmentation was significantly $\left(X^{2}=10.86, \mathrm{df}=2\right.$, $\mathrm{p}=0.004$, Nagelkerke $=0.199$ ) associated with $\mathrm{LOOH}$ and $-\mathrm{SH}$ groups (both inversely). Increased AOPP significantly predicted caesarian section $\left(X^{2}=9.51, d f=1, p=0.007\right.$, Nagelkerke $\left.=0.194\right)$. Lowered $-\mathrm{SH}$ groups and TRAP values at the end of term predict inadequate breast milk flow the first week after delivery $\left(X^{2}=14.30, d f=2, p=0.001\right.$, Nagelkerke $=0.301$ ). Lowered PON1 activity at the end of term significantly predicts baby sucking problems the first week after delivery $\left(X^{2}=6.16, d f=1, p=0.013\right.$, Nagelkerke $\left.=0.143\right)$.

\section{Discussion}

The first major finding of this study is that pregnancy is accompanied by highly significant changes in O\&NS as indicated by increased AOPP and NOx and lowered TRAP and -SH levels findings, which are in agreement with previous reports (Choi et al., 2002; De Lucca et al., 2016; Fialová et al., 2003; Kalousová et al., 2002; SalasPacheco et al., 2016). In normal pregnancy, there is an increase in

Table 3

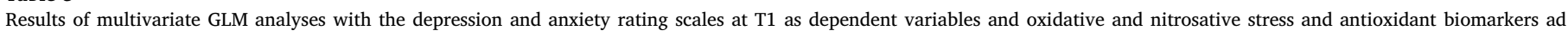
explanatory variables.

\begin{tabular}{|c|c|c|c|c|c|c|}
\hline Tests & Dependent Variables & Explanatory Variables & $\mathbf{F}$ & df & $p$ & Partial Eta Squared \\
\hline \multirow[t]{2}{*}{ Multivariate \#1 } & \multirow[t]{2}{*}{ T1 EPDS, STAI, BDI and HDRS } & AOPP & 12.27 & $4 / 65$ & $<0.001$ & 0.430 \\
\hline & & Lifetime MDD & 4.52 & $4 / 65$ & 0.003 & 0.218 \\
\hline \multirow[t]{8}{*}{ Between-subject effects } & \multirow[t]{2}{*}{ T1 EPDS } & $\operatorname{AOPP}(+)$ & 4.15 & $1 / 68$ & 0.045 & 0.058 \\
\hline & & Lifetime MDD (+) & 12.35 & $1 / 68$ & 0.001 & 0.154 \\
\hline & \multirow[t]{2}{*}{ T1 STAI state } & AOPP $(-)$ & 8.86 & $1 / 68$ & 0.004 & 0.115 \\
\hline & & Lifetime MDD $(+)$ & 10.01 & $1 / 68$ & 0.002 & 0.128 \\
\hline & \multirow[t]{2}{*}{ T1 BDI } & $\mathrm{AOPP}(+)$ & 14.48 & $1 / 68$ & $<0.001$ & 0.176 \\
\hline & & Lifetime MDD $(+)$ & 11.79 & $1 / 68$ & 0.001 & 0.148 \\
\hline & \multirow[t]{2}{*}{ T1 HDRS } & $\mathrm{AOPP}(+)$ & 6.60 & $1 / 68$ & 0.012 & 0.088 \\
\hline & & Lifetime MDD (+) & 17.36 & $1 / 68$ & $<0.001$ & 0.203 \\
\hline \multirow[t]{2}{*}{ Multivariate \#2 } & \multirow[t]{2}{*}{ T1 EPDS, STAI, BDI and HDRS } & NOx & 4.63 & $4 / 65$ & 0.002 & 0.222 \\
\hline & & Lifetime MDD & 4.66 & $4 / 65$ & 0.002 & 0.223 \\
\hline \multirow[t]{2}{*}{ Multivariate \#3 } & \multirow[t]{2}{*}{ T1 EPDS, STAI, BDI and HDRS } & $\mathrm{LOOH}$ & 3.02 & $4 / 65$ & 0.024 & 0.157 \\
\hline & & Lifetime MDD & 4.28 & $4 / 65$ & 0.004 & 0.208 \\
\hline \multirow[t]{2}{*}{ Multivariate \#4 } & \multirow[t]{2}{*}{ T1 EPDS, STAI, BDI and HDRS } & -SH groups & 2.86 & $4 / 65$ & 0.029 & 0.151 \\
\hline & & Lifetime MDD & 4.25 & $4 / 65$ & 0.004 & 0.207 \\
\hline
\end{tabular}

EPDS: Edinburgh Postnatal Depression Scale; STAI: Spielberger's State-Trait Anxiety Inventory; HDRS: The Hamilton Rating Scale for Depression; BDI: Beck Depression Inventory. AOPP: Advanced oxidation protein products; MDD: Major Depressive Disorder; NOx: Nitric oxide metabolites; LOOH: Lipid hydroperoxide; -SH groups: Sulfhydryl groups. 
Table 4

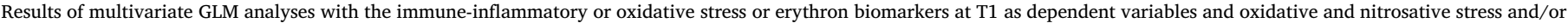
antioxidant biomarkers ad explanatory variables.

\begin{tabular}{|c|c|c|c|c|c|c|}
\hline Tests & Dependent Variables & Explanatory Variables & $\mathbf{F}$ & df & $p$ & Partial Eta Squared \\
\hline \multirow[t]{2}{*}{ Multivariate \#1 } & \multirow[t]{2}{*}{ CRP, Hp and Zinc } & -SH groups & 4.51 & $3 / 66$ & 0.006 & 0.170 \\
\hline & & NOx & 10.54 & $3 / 66$ & $<0.001$ & 0.324 \\
\hline \multirow[t]{4}{*}{ Between-subject effects } & \multirow[t]{2}{*}{ CRP } & -SH groups (-) & 12.20 & $1 / 68$ & 0.001 & 0.152 \\
\hline & & $\operatorname{NOx}(+)$ & 6.56 & $1 / 68$ & 0.013 & 0.088 \\
\hline & Hp & NOx $(+)$ & 7.81 & $1 / 68$ & 0.007 & 0.103 \\
\hline & Zinc & NOx $(-)$ & 21.23 & $1 / 68$ & $<0.001$ & 0.238 \\
\hline \multirow[t]{2}{*}{ Multivariate \#2 } & \multirow[t]{2}{*}{ CRP, Hp and Zinc } & -SH groups & 3.89 & $3 / 66$ & 0.013 & 0.150 \\
\hline & & AOPP & 7.25 & $3 / 66$ & $<0.001$ & 0.248 \\
\hline \multirow[t]{3}{*}{ Between-subject effects } & \multirow[t]{2}{*}{ CRP } & -SH groups (-) & 11.55 & $1 / 68$ & 0.001 & 0.145 \\
\hline & & AOPP $(+)$ & 12.02 & $1 / 68$ & 0.001 & 0.150 \\
\hline & Zinc & AOPP (-) & 13.27 & $1 / 68$ & 0.001 & 0.163 \\
\hline Multivariate \#3 & AOPP, NOx, LOOH and zAOPP + NOx & -SH groups & 7.47 & $3 / 67$ & $<0.001$ & 0.251 \\
\hline \multirow[t]{3}{*}{ Between-subject effects } & AOPP & -SH groups $(-)$ & 20.15 & $1 / 69$ & $<0.001$ & 0.226 \\
\hline & NOx & -SH groups $(-)$ & 14.13 & $1 / 69$ & $<0.001$ & 0.170 \\
\hline & $\mathrm{zAOPP}+\mathrm{NOx}$ & -SH groups (-) & 16.09 & $1 / 69$ & $<0.001$ & 0.189 \\
\hline Multivariate \#4 & AOPP, NOx, LOOH and zAOPP + NOx & TRAP $(-)$ & 5.71 & $3 / 67$ & 0.002 & 0.204 \\
\hline \multirow[t]{3}{*}{ Between-subject effects } & AOPP & TRAP (-) & 17.00 & $1 / 69$ & $<0.001$ & 0.198 \\
\hline & NOx & TRAP (-) & 12.44 & $1 / 69$ & 0.001 & 0.153 \\
\hline & $\mathrm{zAOPP}+\mathrm{NOx}$ & TRAP (-) & 13.26 & $1 / 69$ & 0.001 & 0.161 \\
\hline Multivariate \#5 & AOPP, NOx, LOOH and zAOPP + NOx & Zinc & 14.12 & $3 / 67$ & $<0.001$ & 0.387 \\
\hline \multirow[t]{4}{*}{ Between-subject effects } & AOPP & Zinc (-) & 32.03 & $1 / 69$ & $<0.001$ & 0.317 \\
\hline & NOx & Zinc (-) & 18.87 & $1 / 69$ & $<0.001$ & 0.216 \\
\hline & $\mathrm{LOOH}$ & Zinc $(+)$ & 28.34 & $1 / 69$ & $<0.001$ & 0.290 \\
\hline & $\mathrm{zAOPP}+\mathrm{NOx}$ & Zinc (-) & 12.18 & $1 / 69$ & 0.001 & 0.150 \\
\hline \multirow[t]{2}{*}{ Multivariate \#6 } & MCV and Hct & $\mathrm{LOOH}$ & 5.85 & $2 / 39$ & 0.006 & 0.231 \\
\hline & & CRP & 5.86 & $1 / 39$ & 0.006 & 0.231 \\
\hline \multirow[t]{2}{*}{ Between-subject effects } & Het & $\operatorname{CRP}(+)$ & 11.82 & $1 / 40$ & 0.001 & 0.228 \\
\hline & MCV & $\mathrm{LOOH}(+)$ & 11.95 & $1 / 40$ & 0.001 & 0.230 \\
\hline
\end{tabular}

CRP: c-reactive protein.

Hp: Haptoglobin.

AOPP: Advanced oxidation protein products.

NOx: Nitric oxide metabolites.

LOOH: Hydroperoxide.

zAOPP + NOx: sum of z values of AOPP and NOx.

MCV: Mean corpuscular volume.

Hct: Hematocrit.

-SH groups: Sulfhydryl groups.

reactive oxygen species (ROS) production, due to formation of new tissues, coupled with compensatory elevations in antioxidant defenses (Pereira and Martel, 2014). There are a few papers showing that pregnancy is accompanied by increased AOPP levels, suggesting increased protein oxidation (Fialová et al., 2003, 2006). In contrast to our a priori hypothesis of activated $\mathrm{O} \& \mathrm{NS}$ in pregnancy, we found lowered LOOH levels in pregnancy. Nevertheless, lowered LOOH levels may be a consequence of increased production of AOPP during pregnancy. AOPPs may inhibit free radical production in vitro (Bordignon et al., 2014), while peroxides are used for oxidation of proteins leading to elevated production of AOPP (Colombo et al., 2015; Piwowar, 2010). Lowered peroxide levels may have an evolutionary advantage, but may come at a price when AOPP levels further increase eventually leading to RAGE receptor (Piwowar, 2010) and NF-6B (Wang et al., 2013) activation, and subsequently increased inflammation with elevated IL-6 and COX-2 levels (Piwowar, 2010; Wang et al., 2013).

Increased NOx levels are associated with increased nitrosylation of proteins, which is, when moderate, a protective mechanism (Morris et al., 2016b). Nitrosylation, resulting in increased S-nitrosothiols (SNO), regulates immune and neuronal systems and has antimicrobial and smooth muscle relaxant activities, including on uterine smooth muscles (Morris et al., 2016b; Ulrich et al., 2012). In sheep, pregnancy increases total S-nitrosylation, but decreases S-nitrosylation of endothelial NO synthesizing system (Zhang et al., 2012). Hypernitrosylation, on the other hand, may cause neuro-immune disturbances and neuronal dysfunctions, including neuroprogression and neurodegeneration (Morris et al., 2016b).

Lowered -SH groups in pregnancy may indicate less reductive capacity. Our findings that increased AOPP and NOx levels are inversely associated with -SH levels may be explained by the knowledge that during oxidative processes $\mathrm{NO}$ is bound to $-\mathrm{SH}$ groups thereby forming RSNO (Gaston, 1999). Lowered TRAP levels at the end of pregnancy indicate lowered antioxidant defenses. TRAP is an antioxidant parameter reflecting the sum of hydrophilic, e.g. uric acid, vitamin C and bilirubin, and hydrophobic, e.g. vitamin E, antioxidants (Oxford Biomedical Research, 2010). Importantly, we found that lowered levels of TRAP and zinc, another strong antioxidant which is decreased in pregnancy (Mihu et al., 2012; Roomruangwong et al., 2016c), are strongly associated with increased O \& NS, AOPP and NOx formation, suggesting that lowered antioxidant defenses during pregnancy could further aggravate $O$ \& NS. For example, vitamin C, one of the components of TRAP, reduces reactive oxygen and nitrogen species (Noyan et al., 2006), thereby attenuating oxidative stress and normalizing AOPP levels (Mahfouz and Kummerow, 2004). Contrary to our $a$ priori hypothesis we could not find a significant decrease in PON1 activities in pregnant women. Previous studies reported on lowered PON1 activities in complicated pregnancies, including pregnant women with gestational diabetes (Li et al., 2016), obesity, increased BMI or smoking (Ardalić et al., 2014; Ferretti et al., 2014; Maes et al., 2012). In our study, however, most pregnant women had uncomplicated pregnancies, did not smoke and had normal BMI.

The second major finding of our study is that AOPP and NOx production are associated with prenatal depressive symptoms and that $\mathrm{O} \&$ NS indexes predict postnatal depressive symptoms. These findings extend previous reports on increased AOPP in subgroups of depressed patients (Vargas et al., 2013a), and increased iNOS production (Gałecki 
Table 5

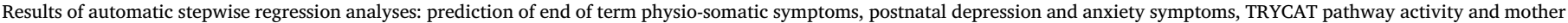
and baby characteristics as dependent variables and oxidative stress biomarkers as explanatory variables.

\begin{tabular}{|c|c|c|c|c|c|c|c|}
\hline \multirow[t]{2}{*}{ Dependent variables } & \multirow[t]{2}{*}{ Explanatory variables } & \multirow[t]{2}{*}{$\mathbf{t}$} & \multirow[t]{2}{*}{$\mathbf{P}$} & \multicolumn{4}{|l|}{ Model } \\
\hline & & & & $\mathbf{R}^{2}$ & $\mathbf{F}$ & df & $\mathbf{p}$ \\
\hline \multirow[t]{3}{*}{ \#1. T1 PC physio-somatic symptoms } & zOX/ANTIOX & +3.04 & 0.003 & 0.350 & 12.38 & $3 / 69$ & $<0.001$ \\
\hline & $\mathrm{LOOH}$ & -2.38 & 0.020 & & & & \\
\hline & $-\mathrm{SH}$ groups & -2.10 & 0.039 & & & & \\
\hline \multirow[t]{3}{*}{ \#2. T1 PC Physio-somatic symptoms } & PON1 total activity & -2.17 & 0.034 & 0.487 & 21.17 & $3 / 67$ & $<0.001$ \\
\hline & CRP & +3.01 & 0.004 & & & & \\
\hline & Zinc & -4.92 & $<0.001$ & & & & \\
\hline \multirow[t]{2}{*}{ \#3. T2 HDRS } & $\mathrm{zAOPP}+\mathrm{NOx}$ & +2.38 & 0.021 & 0.206 & 7.80 & $2 / 60$ & 0.001 \\
\hline & $\mathrm{LOOH}$ & -2.19 & 0.033 & & & & \\
\hline \#4. T2 BDI & zOX/ANTIOX & +3.47 & 0.001 & 0.147 & 12.05 & $1 / 70$ & 0.001 \\
\hline \#5. T2 STAI state & zOX/ANTIOX & -6.17 & $<0.001$ & 0.380 & 38.00 & $1 / 62$ & $<0.001$ \\
\hline \#6. 2 IgA Kyn-TRY & $\mathrm{zAOPP}+\mathrm{NOx}$ & -4.70 & $<0.001$ & 0.243 & 22.11 & $1 / 69$ & $<0.001$ \\
\hline \#7. 2 IgA Kyn-TRY & AOPP & -4.25 & $<0.001$ & 0.207 & 18.02 & $1 / 69$ & $<0.001$ \\
\hline \multirow[t]{2}{*}{ \#8. 2 IgA Kyn-TRY } & NOx & -2.56 & 0.013 & 0.211 & 10.37 & $2 / 68$ & $<0.001$ \\
\hline & CRP & -2.21 & 0.031 & & & & \\
\hline \multirow[t]{2}{*}{ \#9. Duration labor } & PON1 total activity & -2.56 & 0.015 & 0.241 & 6.04 & $2 / 38$ & 0.005 \\
\hline & CRP & -2.51 & 0.017 & & & & \\
\hline \multirow[t]{2}{*}{$\# 10$. Cord length } & AOPP & -3.58 & 0.001 & 0.331 & 9.41 & $2 / 38$ & $<0.001$ \\
\hline & PON1 total activity & +2.63 & 0.012 & & & & \\
\hline \multirow[t]{2}{*}{ \#11. Duration baby awake first 4 weeks after delivery } & PON1 total activity & -4.97 & $<0.001$ & 0.427 & 13.77 & $2 / 37$ & $<0.001$ \\
\hline & RR genotype & -3.21 & 0.001 & & & & \\
\hline
\end{tabular}

T2 HDRS: The Hamilton Rating Scale for Depression at T2 (48-72 $\mathrm{h}$ after delivery).

T2 BDI: Beck Depression Inventory at T2 (48-72 h after delivery).

T2 STAI: Spielberger's State-Trait Anxiety Inventory at T2 (48-72 h after delivery).

IgA KYN/TRY: IgA directed to kynurenine - IgA directed to tryptophan.

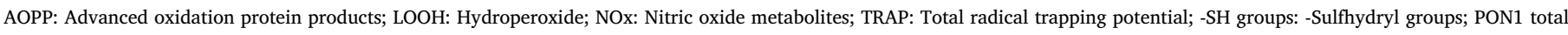
activity: paraoxonase 1 total activity determined using phenylacetate as substrate; CMPAase: PON1 activity determined using CMPA (4-(chloromethyl)phenyl acetate) as substrate. zAOPP + NOx: sum of $z$ values of AOPP and NOx; zTRAP + CMPAase: sum of $z$ values of TRAP + CMPAase; ZOX/ANTIOX: zAOPP + NOx/ zTRAP + CMPAase.

CRP: c-reactive protein.

RR genotype: RR genotype of paroxonase 1 enzyme.

et al., 2012) and autoimmune responses to NO-adducts (reflecting hypernitrosylation) in major depression (Maes et al., 2012). The inverse association between lowered levels of $-\mathrm{SH}$ groups and prenatal depressive symptoms (especially BDI) extend previous findings on - $\mathrm{SH}$ groups in patients with post-stroke depression (Cichoń et al., 2015) and may be explained by increased use of $-\mathrm{SH}$ groups for SNO synthesis. Also, the inverse association between peroxides and depressive symptoms may be explained by increased use of peroxides during AOPP synthesis and inhibition of peroxides by AOPP (Bordignon et al., 2014; Piwowar, 2010). These findings differ from the ones observed in nonpregnancy-related major depression, which is accompanied by increased peroxide levels (Maes et al., 2010). Therefore, protein oxidation rather than lipid peroxidation could be more consistently associated with perinatal depression.

In contrast to our a priori hypotheses we could not detect that lowered levels of TRAP and PON1 activity are inversely associated with perinatal depressive symptoms. Previous studies (Chang et al., 2015) found lowered TRAP levels in depression and an inverse correlation between TRAP and HDRS score, and lowered TRAP levels in individuals with a history of suicide attempts (Vargas et al., 2013b). Previous studies reported that PON1 serum activity may be lowered (Bortolasci et al., 2014) or not (Kodydková et al., 2009) in major depression.

Interestingly, while some O \& NS biomarkers, namely AOPP and NOx, are positively correlated with perinatal depression scores, they are negatively related to anxiety especially to postnatal anxiety scores. It may be that, in the perinatal period, depression and anxiety symptoms are regulated in a different way. For example, NO plays a key role in stress regulation (Morris et al., 2016a), while NO and NOS enzymes are found in brain regions which are involved in anxiety, including hypothalamus, amygdala, and hippocampus (Toda et al., 2009). Acute

Table 6

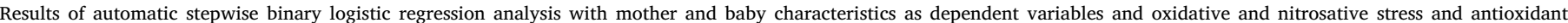
biomarkers as explanatory variables.

\begin{tabular}{|c|c|c|c|c|c|c|c|}
\hline Number & Dependent variables & Explanatory variables & Wald & df & $\mathbf{p}$ & OR & $95 \% \mathrm{CI}$ \\
\hline \multirow[t]{2}{*}{$\# 1$} & T1 Hyperpigmentation & -SH groups & 4.43 & 1 & 0.035 & 0.31 & $0.11-0.92$ \\
\hline & & $\mathrm{LOOH}$ & 7.33 & 1 & 0.007 & 0.21 & $0.07-0.65$ \\
\hline$\# 2$ & Caesarean section & AOPP & 7.18 & 1 & 0.007 & 4.42 & $1.49-13.10$ \\
\hline \multirow[t]{2}{*}{$\# 3$} & Inadequate breast milk flow first week after delivery & -SH groups & 4.91 & 1 & 0.027 & 0.26 & $0.08-0.86$ \\
\hline & & TRAP & 6.86 & 1 & 0.009 & 0.45 & $0.29-0.82$ \\
\hline \#4 & Baby sucking problem first week after delivery & PON1 total activity & 4.64 & 1 & 0.031 & 0.41 & $0.19-0.92$ \\
\hline
\end{tabular}

OR: Odds ratio.

95\% CI: 95\% confidence intervals, upper and lower limit.

LOOH: Lipid hydroperoxides.

TRAP: Total radical trapping potential.

-SH groups: Sulfhydryl groups.

AOPP: Advanced oxidation protein products.

PON1 total activity: paraoxonase 1 total activity determined using phenylacetate as substrate. 
restraint stress exposure (a model of anxiogenesis) is associated with lowered NOx production, whereas these effects are not detected in chronic restraint stress exposure (a model of depression) (Morris et al., 2016a).

The third major finding of this study is that physio-somatic symptoms at the end of term are strongly related to O \& NS, increased AOPP and NOx and to lower -SH and $\mathrm{LOOH}$ levels and after considering the effects of zinc (negative association) and CRP (positive association) also with lower PON1 total activity. Previously it was shown that physiosomatic symptoms in depression and chronic fatigue syndrome (CFS), a neuro-immune disorder characterized by physio-somatic symptoms (Maes, 2009a; Maes and Twisk, 2010), are associated with O \& NS and lowered antioxidant levels (Morris et al., 2016a; Morris and Maes, 2013). For example, in CFS IgM responses to oxidative specific epitopes (reflecting lipid peroxidation and oxidative damage to membranes) and NO-adducts (reflecting hypernitrosylation) and antioxidants were associated with fatigue, muscular tension and neurocognitive deficits (Maes, 2009b).

The fourth major finding of this study is that NOx, AOPP and CRP levels are inversely related with TRYCAT pathway activation thereby explaining a lowered kynurenine / tryptophan ratio at the end of term. These inverse associations may indicate negative regulatory effects of NO on IDO activation (Hucke et al., 2004), regulatory effects of nitrosylation attenuating inflammatory responses (Lim et al., 2011), decreased availability of peroxides, which are used for AOPP production (Buonocore et al., 2000), and the anti-inflammatory effects of CRP (Mold and Clos, 2013; Ridker and Lüscher, 2014).

The fifth major finding of this study is that signs of $\mathrm{O}$ \& NS and lowered antioxidant defenses are associated with obstetric complications. A) Erythron variables at the end of term are associated with immune and oxidative stress markers, namely Hct with CRP and MCV with LOOH. During pregnancy, the erythrocyte production rate is increased with younger erythrocytes, which are larger in diameter than old erythrocytes, entering the circulation thereby increasing MCV (Lurie and Mamet, 2000). Oxidative stress may decrease new erythrocyte production leaving older red cells in the circulation, thereby decreasing MCV (Lurie and Mamet, 2000). B) Hyperpigmentation at the end of term is inversely associated with - $\mathrm{SH}$ groups and $\mathrm{LOOH}$. Interestingly, patients with melasma have increased oxidative stress compared with controls (Seçkin et al., 2014), while increased NO elicits activation of tyrosinase (Roméro-Graillet et al., 1996), which is responsible for melanin synthesis in melanocytes, leading to skin hyperpigmentation (Novellino et al., 1998). C) Duration of labor is inversely correlated with PON1 total activity and CRP. There is evidence that placental membranes promote labor and delivery of both fetus and placenta (Menon, 2016). Indeed, placental membrane cells enter senescence prior to labor (Behnia et al., 2015) and this may increase intrauterine inflammation promoting delivery (Menon et al., 2016). PON1 has anti-inflammatory properties (Escribano et al., 2015; Furlong et al., 2016), while CRP has both pro- and anti-inflammatory properties (Thiele et al., 2014) and thus changing levels of these compounds could interfere with mechanisms leading to labor. D) Caesarean section was strongly predicted by increased AOPP levels. Previous reports did not find significant differences in lipid peroxidation, thiol molecules (sulfhydryl) and total antioxidant power between women with vaginal delivery and caesarian delivery (Vakilian et al., 2009). Interestingly, neonates born via Caesarean delivery are predisposed to pathological conditions related to changes in antioxidant levels (Nejad et al., 2016), while increased oxidative stress in neonates contributes to chronic lung disease and neonatal respiratory distress syndrome (Tsukahara et al., 2004). Future research should examine the relationship between increased protein oxidation at the end of term and fetal distress syndrome, characterized by increased reactive oxygen species and lower catalase activity as a consequence of fetal hypoxia (Raicević et al., 2010). Indeed the latter is an indication to Caesarean section. E) There was an inverse association between lowered -SH groups and TRAP at the end of term and inadequate breast milk flow one week after delivery. Milk flow depends on both milk production and lactation whereby prolactin and oxytocin play key roles (Hill et al., 1999). There is a negative correlation between maternal post-caesarean section oxidative stress indices and serum oxytocin (Stanić et al., 2016; Yuksel et al., 2016). Thus, mothers with increased O \& NS, and by inference lowered antioxidant levels, may have decreased levels of oxytocin leading to lower breast milk flow. F) Cord length was inversely associated with AOPP but positively with PON1. Such findings may be explained by oxidative effects on newly formed tissues. G) Lowered PON1 activity at the end of term predicts duration of baby awakenings at night and feeding problems, suggesting that increased O \& NS or inflammation as a consequence of decreased PON1 may increase risk towards behavioral problems (sleep and feeding) in neonates.

This paper has some limitations and strengths. A potential limitation is that, this study is a cross-sectional study and thus no inferences can be made on causality, which should be considered when interpreting the results. A second limitation is that it would have been more interesting if we had determined another marker of lipid peroxidation, such as malondialdehyde, to examine the effects of protein versus lipid peroxidation. A strength is that we employed multivariate GLM analyses and controlled our data for confounding variables, including age and BMI.

\section{Acknowledgement}

This research has been supported by the Ratchadaphiseksomphot Endowment Fund 2013 of Chulalongkorn University (CU-56-457-HR).

\section{References}

Anderson, G., Maes, M., 2013. Postpartum depression: psychoneuroimmunological un derpinnings and treatment. Neuropsychiatr. Dis. Treat. 9, 277-287.

Anderson, G., Maes, M., 2014. Oxidative/nitrosative stress and immuno-inflammatory pathways in depression: treatment implications. Curr. Pharm. Des. 20, 3812-3847.

Anderson, G., Maes, M., 2016. How immune-inflammatory processes link CNS and psychiatric disorders: classification and treatment implications. CNS Neurol. Disord. Drug Targets (Nov 22) (Epub ahead of print).

Ardalić, D., Stefanović, A., Kotur-Stevuljević, J., Vujović, A., Spasić, S., SpasojevićKaliomanvska, V., Jelić-Ivanović, Z., Mandić-Marković, V., Miković, Z., Cerović, N., 2014. The influence of maternal smoking habits before pregnancy and antioxidative supplementation during pregnancy on oxidative stress status in a non-complicated pregnancy. Adv. Clin. Exp. Med 23, 575-583.

Barim, A.O., Aydin, S., Colak, R., Dag, E., Deniz, O., Sahin, I., 2009. Ghrelin, paraoxonase and arylesterase levels in depressive patients before and after citalopram treatment. Clin. Biochem 42, 1076-1081.

Beck, A.T., Steer, R.A., Garbin, M.G.J., 1988. Psychometric properties of the Beck Depression Inventory Twenty-five years of evaluation. Clin. Psych. Rev. 8, 77-100.

Behnia, F., Taylor, B.D., Woodson, M., Kacerovsky, M., Hawkins, H., Fortunato, S.J., Saade, G.R., Menon, R., 2015. Chorioamniotic Membrane Senescence: a Signal for Parturition? Am. J. Obstet. Gynecol. 213, e1-e16.

Bordignon, M., Da Dalt, L., Marinelli, L., Gabai, G., 2014. Advanced oxidation protein products are generated by bovine neutrophils and inhibit free radical production in vitro. Vet. J. 199, 162-168.

Bortolasci, C.C., Vargas, H.O., Souza-Nogueira, A., Barbosa, D.S., Moreira, E.G., Nunes, S.O., Berk, M., Dodd, S., Maes, M., 2014. Lowered plasma paraoxonase (PON)1 activity is a trait marker of major depression and PON1 Q192R gene polymorphismsmoking interactions differentially predict the odds of major depression and bipolar disorder. J. Affect Disord. 159, 23-30.

Buonocore, G., Perrone, S., Longini, M., Terzuoli, L., Bracci, R., 2000. Total hydroperoxide and advanced oxidation protein products in preterm hypoxic babies. Pediatr. Res 47, 221-224.

Camkurt, M.A., Fındıklı, E., İzci, F., Kurutaş, E.B., Tuman, T.C., 2016. Evaluation of malondialdehyde, superoxide dismutase and catalase activity and their diagnostic value in drug naïve, first episode, non-smoker major depression patients and healthy controls. Psychiatry Res 238, 81-85.

Chang, C.C., Lee, C.T., Lan, T.H., Ju, P.C., Hsieh, Y.H., Lai, T.J., 2015. Effects of antidepressant treatment on total antioxidant capacity and free radical levels in patients with major depressive disorder. Psychiatry Res 230, 575-580.

Choi, J.W., Im, M.W., Pai, S.H., 2002. Nitric oxide production increases during normal pregnancy and decreases in preeclampsia. Ann. Clin. Lab Sci. 32, 257-263.

Cichoń, N., Bijak, M., Miller, E., Niwald, M., Saluk, J., 2015. Poststroke depression as a factor adversely affecting the level of oxidative damage to plasma proteins during a brain stroke. Oxid. Med Cell Longev. 2015, 408745.

Colombo, G., Clerici, M., Giustarini, D., Portinaro, N., Badalamenti, S., Rossi, R., Milzani, A., Dalle-Donne, I., 2015. A central role for intermolecular dityrosine cross-linking of 
fibrinogen in high molecular weight advanced oxidation protein product (AOPP) formation. Biochim Biophys. Acta 1850, 1-12.

De Lucca, L., Rodrigues, F., Jantsch, L.B., Neme, W.S., Gallarreta, F.M., Gonçalves, T.L., 2016. Oxidative Profile and $\delta$-Aminolevulinate Dehydratase Activity in Healthy Pregnant Women with Iron Supplementation. Int J. Environ. Res Public Health 13, E463.

De Vriese, S.R., Christophe, A.B., Maes, M., 2003. Lowered serum n-3 polyunsaturated fatty acid (PUFA) levels predict the occurrence of postpartum depression: further evidence that lowered n-PUFAs are related to major depression. Life Sci. 73, 3181-3187.

Duhig, K., Chappell, L.C., Shennan, A.H., 2016. Oxidative stress in pregnancy and reproduction. Obstet. Med 9, 113-116.

Escribano, D., Tvarijonaviciute, A., Tecles, F., Cerón, J.J., 2015. Serum paraoxonase type1 activity in pigs: assay validation and evolution after an induced experimental inflammation. Vet. Immunol. Immunopathol. 163, 210-215.

Ferretti, G., Cester, A.M., Bacchetti, T., Raffaelli, F., Vignini, A., Orici, F., Martino, C., Tranquilli, A., 2014. Leptin and paraoxonase activity in cord blood from obese mothers. J. Matern Fetal Neonatal Med 27, 1353-1356.

Fialová, L., Kalousová, M., Soukupová, J., Malbohan, I., Krofta, L., Mikulíková, L., Horejsová, H., Stípek, S., Zima, T., 2003. Levels of advanced oxidation protein products (AOPP) in the first trimester of pregnancy. Sb. Lek. 104, 95-102.

Fialová, L., Malbohan, I., Kalousová, M., Soukupová, J., Krofta, L., Stípek, S., Zima, T., 2006. Oxidative stress and inflammation in pregnancy. Scand. J. Clin. Lab Invest 66, 121-127.

Furlong, C.E., Holland, N., Richter, R.J., Bradman, A., Ho, A., Eskenazi, B., 2006. PON1 status of farmworker mothers and children as a predictor of organophosphate sensitivity. Pharm. Genom. 16, 183-190.

Furlong, C.E., Marsillach, J., Jarvik, G.P., Costa, L.G., 2016. Paraoxonases-1, -2 and -3: what are their functions? Chem. Biol. Interact. 259, 51-62.

Gałecki, P., Gałecka, E., Maes, M., Chamielec, M., Orzechowska, A., Bobińska, K., Lewiński, A., Szemraj, J., 2012. The expression of genes encoding for COX-2, MPO, iNOS, and sPLA2-IIA in patients with recurrent depressive disorder. J. Affect Disord. 138, 360-366.

Gaston, B., 1999. Nitric oxide and thiol groups. Biochim Biophys. Acta 1411, 323-333.

Gonzalez Flecha, B.S., Repetto, M., Evelson, P., Boveris, A., 1991. Inhibition of microsomal lipid peroxidation by $\alpha$-tocopherol and $\alpha$-tocopherol acetate. Xenobiotica 21, 1013-1022.

Hamilton, M., 2000. Hamilton rating scale for Depression (Ham-D). Handbook of psychiatric measures. APA, Washington DC, pp. 526-528.

Hanasand, M., Omdal, R., Norheim, K.B., Gøransson, L.G., Brede, C., Jonsson, G., 2012. Improved detection of advanced oxidation protein products in plasma. Clin. Chim. Acta 413, 901-906.

Hill, P.D., Chatterton, R.T.J., Aldag, J.C., 1999. Serum prolactin in breastfeeding: state of the science. Biol. Res Nurs. 1, 65-75.

Horasut, S., Photisak, S., Glander, J., 1997. Thai version of the Beck depression Inventory (BDI). Bull. Suanprung 13, 22-28.

Hu, M.L., 1994. Measurement of protein thiol groups and glutathione in plasma. Methods Enzymol. 233, 380-385.

Hucke, C., MacKenzie, C.R., Adjogble, K.D., Takikawa, O., Däubener, W., 2004. Nitric oxide-mediated regulation of gamma interferon-induced bacteriostasis: inhibition and degradation of human indoleamine 2,3-dioxygenase. Infect. Immun. 72, 2723-2730.

Jung, A., Spira, D., Steinhagen-Thiessen, E., Demuth, I., Norman, K., 2016. Zinc Deficiency Is associated With Depressive Symptoms-Results From the Berlin Aging Study II. J. Gerontol. A Biol. Sci. Med Sci (Epub ahead of print).

Kalousová, M., Fialová, L., Zima, T., Malbohan, I.M., Krofta, L., Soukupová, J., Mikulíková, L., Stípek, S., 2002. Advanced oxidation protein products in pregnancy. Ceska Gynekol. 67, 194-197.

Kirbas, A., Daglar, K., Gencosmanoglu, G., Yilmaz, Z., Timur, H., Inal, Z., Yucel, A., Danisman, N., 2016. Total oxidative and anti-oxidative status, and ADAMTS-12 levels in placenta previa and early-onset severe preeclampsia. Pregnancy Hypertens. 6, 295-299.

Kodydková, J., Vávrová, L., Zeman, M., Jirák, R., Macásek, J., Stanková, B., Tvrzická, E., Zák, A., 2009. Antioxidative enzymes and increased oxidative stress in depressive women. Clin. Biochem 42, 1368-1374.

Leff-Gelman, P., Mancilla-Herrera, I., Flores-Ramos, M., Cruz-Fuentes, C., Reyes-Grajeda, J.P., García-Cuétara Mdel, P., Bugnot-Pérez, M.D., Pulido-Ascencio, D.E., 2016. The immune system and the role of inflammation in perinatal depression. Neurosci. Bull. 32, 398-420.

Li, H., Yin, Q., Li, N., Ouyang, Z., Zhong, M., 2016. Plasma markers of oxidative stress in patients with gestational diabetes mellitus in the second and third trimester. Obstet. Gynecol. Int 2016, 3865454.

Lim, S.Y., Raftery, M.J., Geczy, C.L., 2011. Oxidative modifications of DAMPs suppress inflammation: the case for S100A8 and S100A9. Antioxid. Redox Signal 15, 2235-2248.

Liu, T., Zhong, S., Liao, X., Chen, J., He, T., Lai, S., Jia, Y., 2015. A meta-analysis of oxidative stress markers in depression. PLoS One 10, e0138904.

Lotrakul, M., Sukkhanit, P., Sukying, C., 1996. The development of Hamilton Rating scale for depression - Thai version. J. Psychiatr. Assoc. Thai 41, 235-246.

Lurie, S., Mamet, Y., 2000. Red blood cell survival and kinetics during pregnancy. Eur. J. Obstet. Gynecol. Reprod. Biol. 93, 185-192.

Ma, Y., Shen, X., Zhang, D., 2015. The relationship between serum zinc level and preeclampsia: a meta-analysis. Nutrients 7, 7806-7820.

Maes, M., 1993. A review on the acute phase response in major depression. Rev. Neurosci. 4, 407-416.

Maes, M., 2008. The cytokine hypothesis of depression: inflammation, oxidative \& nitrosative stress (IO \& NS) and leaky gut as new targets for adjunctive treatments in depression. Neuro Endocrinol. Lett. 29, 287-291.

Maes, M., 2009a. "Functional" or "psychosomatic" symptoms, e.g. a flu-like malaise, aches and pain and fatigue, are major features of major and in particular of melancholic depression. Neuro Endocrinol. Lett. 30, 564-573.

Maes, M., 2009b. Inflammatory and oxidative and nitrosative stress pathways underpinning chronic fatigue, somatization and psychosomatic symptoms. Curr. Opin. Psychiatry 22, 75-83.

Maes, M., Claes, M., Schotte, C., Delbeke, L., Jacquemyn, Y., Verkerk, R., De Meester, I., Scharpé, S., 1992. Disturbances in dexamethasone suppression test and lower availability of L-tryptophan and tyrosine in early puerperium and in women under contraceptive therapy. J. Psychosom. Res 36, 191-197.

Maes, M., Fisar, Z., Medina, M., Scapagnini, G., Nowak, G., Berk, M., 2012. New drug targets in depression: inflammatory, cell-mediated immune, oxidative and nitrosative stress, mitochondrial, antioxidant, and neuroprogressive pathways. And new drug candidates-Nrf2 activators and GSK-3 inhibitors. Inflammopharmacology 20, $127-150$.

Maes, M., Galecki, P., Chang, Y.S., Berk, M., 2011a. A review on the oxidative and nitrosative stress (O\&NS) pathways in major depression and their possible contribution to the (neuro)degenerative processes in that illness. Prog. Neuropsychopharmacol. Biol. Psychiatry 35, 676-692.

Maes, M., Leonard, B.E., Myint, A.M., Kubera, M., Verkerk, R., 2011b. The new '5-HT' hypothesis of depression: cell-mediated immune activation induces indoleamine 2,3dioxygenase, which leads to lower plasma tryptophan and an increased synthesis of detrimental tryptophan catabolites (TRYCATs), both of which contribute to the onset of depression. Prog. Neuropsychopharmacol. Biol. Psychiatry 35, 702-721.

Maes, M., Lin, A.H., Ombelet, W., Stevens, K., Kenis, G., De Jong, R., Cox, J., Bosmans, E., 2000. Immune activation in the early puerperium is related to postpartum axiety and depressive symptoms. Psychoneuroendocrinology 25, 121-137.

Maes, M., Mihaylova, I., Kubera, M., Uytterhoeven, M., Vrydags, N., Bosmans, E., 2010. Increased plasma peroxides and serum oxidized low density lipoprotein antibodies in major depression: markers that further explain the higher incidence of neurodegeneration and coronary artery disease. J. Affect Disord. 125, 287-294.

Maes, M., Mihaylova, I., Leunis, J.C., 2006. Chronic fatigue syndrome is accompanied by an IgM-related immune response directed against neopitopes formed by oxidative or nitrosative damage to lipids and proteins. Neuro Endocrinol. Lett. 27, 615-621.

Maes, M., Noto, C., Brietzke, E., 2015. Omics-based depression and inflammation research. Rev. Bras. Psiquiatr 37, 1-2.

Maes, M., Nowak, G., Caso, J.R., Leza, J.C., Song, C., Kubera, M., Klein, H., Galecki, P., Noto, C., Glaab, E., Balling, R., Berk, M., 2016. Toward omics-based, systems biomedicine, and path and drug discovery methodologies for depression-inflammation research. Mol. Neurobiol. 53, 2927-2935.

Maes, M., Ombelet, W., Libbrecht, I.I., Stevens, K., Kenis, G., De Jongh, R., Lin, A.H., Cox, J., Bosmans, E., 1999. Effects of pregnancy and delivery on serum concentrations of Clara Cell Protein (CC16), an endogenous anticytokine: lower serum CC16 is related to postpartum depression. Psychiatry Res. 87, 117-127.

Maes, M., Ombelet, W., Verkerk, R., Bosmans, E., Scharpé, S., 2001. Effects of pregnancy and delivery on the availability of plasma tryptophan to the brain: relationships to delivery-induced immune activation and early post-partum anxiety and depression. Psychol. Med 31, 847-858.

Maes, M., Stevens, W.J., Declerck, L.S., Bridts, C.H., Peeters, D., Schotte, C., Cosyns, P., 1993. Significantly increased expression of T-cell activation markers (interleukin-2 and HLA-DR) in depression: further evidence for an inflammatory process during that illness. Prog. Neuropsychopharmacol. Biol. Psychiatry 17, 241-255.

Maes, M., Twisk, F.N., 2010. Chronic fatigue syndrome: harvey and Wessely's (bio)psychosocial model versus a bio(psychosocial) model based on inflammatory and oxidative and nitrosative stress pathways. BMC Med. 8, 35.

Mahfouz, M.M., Kummerow, F.A., 2004. Vitamin C or Vitamin B6 supplementation prevent the oxidative stress and decrease of prostacyclin generation in homocysteinemic rats. Int J. Biochem Cell Biol. 36, 1919-1932.

Marseglia, L., D’Angelo, G., Manti, S., Arrigo, T., Barberi, I., Reiter, R.J., Gitto, E., 2014. Oxidative stress-mediated aging during the fetal and perinatal periods. Oxid. Med. Cell. Longev. 2014, 1-8.

Maurya, P.K., Noto, C., Rizzo, L.B., Rios, A.C., Nunes, S.O., Barbosa, D.S., Sethi, S., Zeni, M., Mansur, R.B., Maes, M., Brietzke, E., 2016. The role of oxidative and nitrosative stress in accelerated aging and major depressive disorder. Prog. Neuropsychopharmacol. Biol. Psychiatry 65, 134-144.

Menon, R., 2016. Human fetal membranes at term: dead tissue or signalers of parturition? Placenta 44, 1-5.

Menon, R., Behnia, F., Polettini, J., Saade, G.R., Campisi, J., Velarde, M., 2016. Placental membrane aging and HMGB1 signaling associated with human parturition. Aging (Albany NY) 8, 216-230.

Mihu, D., Sabău, L., Costin, N., Ciortea, R., Măluţan, A., Mihu, C.M., 2012. Implications of maternal systemic oxidative stress in normal pregnancy and in pregnancy complicated by preeclampsia. J. Matern Fetal Neonatal. Med. 25, 944-951.

Mold, C., Clos, T.W., 2013. C-reactive protein inhibits plasmacytoid dendritic cell interferon responses to autoantibody immune complexes. Arthritis Rheum. 65, 1891-1901.

Morris, G., Berk, M., Galecki, P., Walder, K., Maes, M., 2016a. The neuro-immune pathophysiology of central and peripheral fatigue in systemic immune-inflammatory and neuro-immune diseases. Mol. Neurobiol. 53, 1195-1219.

Morris, G., Berk, M., Klein, H., Walder, K., Galecki, P., Maes, M., 2016b. Nitrosative stress, Hypernitrosylation, and autoimmune responses to Nitrosylated proteins: new pathways in neuroprogressive disorders including depression and chronic fatigue syndrome. Mol. Neurobiol (Jun 23) (Epub ahead of print).

Morris, G., Maes, M., 2013. Myalgic encephalomyelitis/chronic fatigue syndrome and 
encephalomyelitis disseminata/multiple sclerosis show remarkable levels of similarity in phenomenology and neuroimmune characteristics. BMC Med. 11, 205.

Moylan, S., Berk, M., Dean, O.M., Samuni, Y., Williams, L.J., O'Neil, A., Hayley, A.C., Pasco, J.A., Anderson, G., Jacka, F.N., Maes, M., 2014. Oxidative \& nitrosative stress in depression: why so much stress? Neurosci. Biobehav Rev. 45, 46-62.

Mukhopadhyay, B., Gongopadhyay, A.N., Rani, A., Gavel, R., Mishra, S.P., 2015. Free radicals and antioxidants status in neonates with congenital malformation. J. Indian Assoc. Pediatr. Surg. 20, 179-183.

Navarro-Gonzálvez, J.A., García-Benayas, C., Arenas, J., 1998. Semiautomated measurement of nitrate in biological fluids. Clin. Chem. 44, 679-681.

Nejad, R.K., Goodarzi, M.T., Shfiee, G., Pezeshki, N., Sohrabi, M., 2016. Comparison of Oxidative Stress Markers and Serum Cortisol between Normal Labor and Selective Cesarean Section Born Neonates. J. Clin. Diagn. Res. 10, BC01-BC03.

Nicholson, L., Lecour, S., Wedegärtner, S., Kindermann, I., Böhm, M., Sliwa, K., 2016. Assessing perinatal depression as an indicator of risk for pregnancy-associated cardiovascular disease. Cardiovasc J. Afr. 27, 119-122.

Nossier, S.A., Naeim, N.E., El-Sayed, N.A., Abu Zeid, A.A., 2015. The effect of zinc supplementation on pregnancy outcomes: a double-blind, randomised controlled trial, Egypt. Br. J. Nutr. 114, 274-285.

Noutsios, G.T., Floros, J., 2014. Childhood asthma: causes, risks, and protective factors; a role of innate immunity. Swiss Med. Wkly 144, w14036.

Novellino, L., d'Ischia, M., Prota, G., 1998. Nitric oxide-induced oxidation of 5,6-dihydroxyindole and 5,6-dihydroxyindole-2-carboxylic acid under aerobic conditions: non-enzymatic route to melanin pigments of potential relevance to skin (photo) protection. Biochim. Biophys. Acta 1425, 27-35.

Noyan, T., Güler, A., Sekeroğlu, M.R., Kamaci, M., 2006. Serum advanced oxidation protein products, myeloperoxidase and ascorbic acid in pre-eclampsia and eclampsia. Aust. N. Z. J. Obstet. Gynaecol. 46, 486-491.

Oxford Biomedical Research, 2010. Antioxidants and their Measurement. Oxford Biomedical Research.

Panis, C., Herrera, A.C.S.A., Victorino, V.J., Campos, F.C., Freitas, L.F., De Rossi, T., Colado Simão, A.N., Cecchini, A.L., Cecchini, R., 2012. Oxidative stress and hematological profiles of advanced breast cancer patients subjected to paclitaxel or doxorubicin chemotherapy. Breast Cancer Res. Treat. 133, 89-97.

Patil, S.B., Kodliwadmath, M.V., Kodliwadmath, S.M., 2006. Lipid peroxidation and nonenzymatic antioxidants in normal pregnancy. J. Obstet. Gynecol. India 56, 399-401.

Peng, Y.F., Pan, G.G., 2017. Red blood cell distribution width predicts homocysteine levels in adult population without vitamin B12 and folate deficiencies. Int J. Cardiol. $227,8-10$.

Pereira, A.C., Martel, F., 2014. Oxidative stress in pregnancy and fertility pathologies. Cell Biol. Toxicol. 30, 301-312.

Pitanupong, J., Liabsuetrakul, T., Vittayanont, A., 2007. Validation of the Thai Edinburgh Postnatal Depression Scale for screening postpartum depression. Psychiatry Res. 149, 253-259.

Piwowar, A., 2010. Advanced oxidation protein products. Part I. mechanism of the formation, characteristics and property. Pol. Merkur Lek. 28, 166-169.

Raicević, S., Cubrilo, D., Arsenijević, S., Vukcević, G., Zivković, V., Vuletić, M., Barudzić, N., Andjelković, N., Antonović, O., Jakovljević, V., 2010. Oxidative stress in fetal distress: potential prospects for diagnosis. Oxid. Med. Cell Longev. 3, 214-218.

Rejc, B., Kato, Y., Karas-Kuzelicki, N., Osredkar, J., Gersak, K., 2016. Lipid-lysine adducts and modified tyrosines as markers of oxidative stress in the second trimester of pregnancy and their association with infant characteristics. Exp. Ther. Med. 11, 797-805.

Repetto, M., Reides, C., Carretero, M.L.G., Costa, M., Griemberg, G., Llesuy, S., 1996. Oxidative stress in blood of HIV infected patients. Clin. Chim. Acta 255, 107-117.

Richter, R.J., Jarvik, G.P., Furlong, C.E., 2008. Determination of paraoxonase 1 status without the use of toxic organophosphate substrates. Circ. Cardiovasc. Genet. 1, 147-152.

Ridker, P.M., Lüscher, T.F., 2014. Anti-inflammatory therapies for cardiovascular disease. Eur. Heart J. 35, 1782-1791.

Rojekar, M.V., Mogarekar, M.R., 2015. Study of serum paraoxonase and phospholipase activities in pregnant women in relation to birth weight. Minerva Ginecol. 67, 327-333.

Roméro-Graillet, C., Aberdam, E., Biagoli, N., Massabni, W., Ortonne, J.P., Ballotti, R., 1996. Ultraviolet B radiation acts through the nitric oxide and cGMP signal transduction pathway to stimulate melanogenesis in human melanocytes. J. Biol. Chem. 271, 28052-28056.

Roomruangwong, C., Kanchanatawan, B., Sirivichayakul, S., Anderson, G., Carvalho, A.F., Duleu, S., Geffard, M., Maes, M., 2016a. IgA/IgM responses to tryptophan and tryptophan catabolites (TRYCATs) are differently associated with prenatal depression, physio-somatic symptoms at the end of term and premenstrual syndrome. Mol. Neurobiol (Apr 1)(Epub ahead of print).

Roomruangwong, C., Kanchanatawan, B., Sirivichayakul, S., Maes, M., 2016b. Antenatal depression and hematocrit levels as predictors of postpartum depression and anxiety symptoms. Psychiatry Res. 238, 211-217.

Roomruangwong, C., Kanchanatawan, B., Sirivichayakul, S., Mahieu, B., Nowak, G., Maes, M., 2016c. Lower serum zinc and higher CRP strongly predict Prenatal depression and Physio-somatic symptoms, which all together predict postnatal depressive symptoms. Mol. Neurobiol (Feb 5).

Roy, S., Dhobale, M., Dangat, K., Mehendale, S., Lalwani, S., Joshi, S., 2015. Differential oxidative stress levels in mothers with preeclampsia delivering male and female babies. J. Matern Fetal Neonatal. Med. 28, 1973-1980.

Salas-Pacheco, J.M., Lourenco-Jaramillo, D.L., Mendez-Hernandez, E.M., SandovalCarrillo, A.A., Hernandez Rayon, Y.I., Llave-Leon, O., Aguilar-Duran, M., LopezTerrones, M.A., Barraza-Salas, M., Vazquez-Alaniz, F., 2016. Oxidative stress equilibrium during obstetric event in normal pregnancy. J. Matern Fetal Neonatal. Med. 1-5.

Seçkin, H.Y., Kalkan, G., Baş, Y., Akbaş, A., Önder, Y., Özyurt, H., Sahin, M., 2014. Oxidative stress status in patients with melasma. Cutan. Ocul. Toxicol. 33, 212-217.

Sheehan, D.V., Lecrubier, Y., Sheehan, K.H., Amorim, P., Janavs, J., Weiller, E., Hergueta, T., Baker, R., Dunbar, G.C., 1998. The Mini-International neuropsychiatric Interview (M.I.N.I.): the development and validation of a structured diagnostic psychiatric interview for DSM-IV and ICD-10. J. Clin. Psychiatry 59, 22-23.

Spielberger, C.D., Vagg, P.R., 1984. Psychometric properties of the STAI: a reply to Ramanaiah, Franzen, and Schill. J. Pers. Assess. 48, 95-97.

Stanić, D., Plećaš-Solarović, B., Petrović, J., Bogavac-Stanojević, N., Sopić, M., KoturStevuljević, J., Ignjatović, S., Pešić, V., 2016. Hydrogen peroxide-induced oxidative damage in peripheral blood lymphocytes from rats chronically treated with corticosterone: the protective effect of oxytocin treatment. Chem. Biol. Interact. 256, $134-141$.

Styczeń, K., Sowa-Kućma, M., Siwek, M., Dudek, D., Reczyński, W., Szewczyk, B., Misztak, P., Topór-Mądry, R., Opoka, W., Nowak, G., 2016. The serum zinc concentration as a potential biological marker in patients with major depressive disorder. Metab. Brain Dis (Epub ahead of print).

Tabrizi, F.M., Pakdel, F.G., 2014. Serum Level of Some Minerals during Three Trimesters of Pregnancy in Iranian Women and Their Newborns: a Longitudinal Study. Indian J. Clin. Biochem. 29, 174-180.

Thiele, J.R., Habersberger, J., Braig, D., Schmidt, Y., Goerendt, K., Maurer, V., Bannasch, H., Scheichl, A., Woollard, K.J., von Dobschütz, E., Kolodgie, F., Virmani, R., Stark, G.B., Peter, K., Eisenhardt, S.U., 2014. Dissociation of pentameric to monomeric Creactive protein localizes and aggravates inflammation: in vivo proof of a powerful proinflammatory mechanism and a new anti-inflammatory strategy. Circulation 130, 35-50.

Tiwari, A.K., Mahdi, A.A., Zahra, F., Sharma, S., Negi, M.P., 2012. Evaluation of Low Blood Lead Levels and Its Association with Oxidative Stress in Pregnant Anemic Women: a Comparative Prospective Study. Indian J. Clin. Biochem. 27, 246-252.

Toda, N., Ayajiki, K., Okamura, T., 2009. Cerebral blood flow regulation by nitric oxide: recent advances. Pharmacol. Rev. 61, 62-69.

Tsukahara, H., Jiang, M.Z., Ohta, N., Sato, S., Tamura, S., Hiraoka, M., Maeda, M., Mayumi, M., 2004. Oxidative stress in neonates: evaluation using specific biomarkers. Life Sci. 75, 933-938.

Ulrich, C., Quillici, D.R., Schegg, K., Woolsey, R., Nordmeier, A., Buxton, I.L., 2012. Uterine smooth muscle S-nitrosylproteome in pregnancy. Mol. Pharmacol. 81, 143-153.

Vacharaporn, K., Pitanupong, J., Samangsri, N., 2003. Development of The Edinburgh postnatal depression scale Thai version. J. Ment. Health Thail. 11, 164-169.

Vakilian, K., Ranjbar, A., Zarganjfard, A., Mortazavi, M., Vosough-Ghanbari, S., Mashaiee, S., Abdollahi, M., 2009. On the relation of oxidative stress in delivery mode in pregnant women; a toxicological concern. Toxicol. Mech. Methods 19, 94-99.

Vargas, H.O., Nunes, S.O., de Castro, M.R., Vargas, M.M., Barbosa, D.S., Bortolasci, C.C., Venugopal, K., Dodd, S., Berk, M., 2013a. Oxidative stress and inflammatory markers are associated with depression and nicotine dependence. Neurosci. Lett. 544, $136-140$.

Vargas, H.O., Nunes, S.O., Pizzo de Castro, M., Bortolasci, C.C., Sabbatini Barbosa, D., Kaminami Morimoto, H., Venugopal, K., Dodd, S., Maes, M., Berk, M., 2013b. Oxidative stress and lowered total antioxidant status are associated with a history of suicide attempts. J. Affect Disord. 150, 923-930.

Waggiallah, H., Alzohairy, M., 2011. The effect of oxidative stress on human red cells glutathione peroxidase, glutathione reductase level, and prevalence of anemia among diabetics. N. Am. J. Med Sci. 3, 344-347.

Walsh, S.W., 1994. Lipid Peroxidation in Preeclampsia: a review. Hypertens. Pregnancy $13,1-32$.

Wang, J.C., Zhao, Y., Chen, S.J., Long, J., Jia, Q.Q., Zhai, J.D., Zhang, Q., Chen, Y., Long, H.B., 2013. AOPPs induce MCP-1 expression by increasing ROS-mediated activation of the NF-kB pathway in rat mesangial cells: inhibition by sesquiterpene lactones. Cell Physiol. Biochem. 32, 1867-1877.

Yuksel, B., Ital, I., Balaban, O., Kocak, E., Seven, A., Kucur, S.K., Erbakirci, M., Keskin, N., 2016. Immediate breastfeeding and skin-to-skin contact during cesarean section decreases maternal oxidative stress, a prospective randomized case-controlled study. J. Matern Fetal Neonatal Med. 29, 2691-2696.

Zein, S., Rachidi, S., Shami, N., Sharara, I., Cheikh-Ali, K., Gauchez, A.S., Moulis, J.M., Ayoubi, J.M., Salameh, P., Hininger-Favier, I., 2016. Association between iron level, glucose impairment and increased DNA damage during pregnancy. J. Trace Elem. Med. Biol (Nov 18) (Epub ahead of print).

Zhang, H.H., Feng, L., Wang, W., Magness, R.R., Chen, D.B., 2012. Estrogen-responsive nitroso-proteome in uterine artery endothelial cells: role of endothelial nitric oxide synthase and estrogen receptor- $\beta$. J. Cell Physiol. 227, 146-159. 